\title{
Adaptive Feedforward and Feedback Control Schemes for Sliding Mode Controlled Power Converters
}

\author{
Siew-Chong Tan, Member, IEEE, Y. M. Lai, Member, IEEE, Chi K. Tse, Fellow, IEEE, and \\ Martin K. H. Cheung, Student Member, IEEE
}

\begin{abstract}
A major disadvantage of applying sliding mode control to dc/dc converters is that the steady-state switching frequency is affected by line and load variations. This is undesirable as it complicates the design of the input and output filters. To reduce switching frequency deviation in the events of line and load variations, an adaptive feedforward control scheme that varies the hysteresis band according to the change of line input voltage and an adaptive feedback control scheme that varies the control parameter (i.e., sliding coefficient) according to the change of the output load are proposed. This paper presents a thorough investigation into the problem and the effectiveness of the proposed solutions. In addition, methods of implementing the proposed adaptive control strategies are discussed. Experimental results confirm that the adaptive control schemes are capable of reducing the switching frequency variations caused by both line and load variations.
\end{abstract}

Index Terms-Adaptive feedback control, adaptive feedforward control, buck converter, hysteresis modulation, pulse-width-modulation (PWM), sliding mode (SM)control.

\section{INTRODUCTION}

$\mathbf{S}$ LIDING MODE (SM) controllers are well known for their stability and robustness against parameter, line, and load variations (i.e., their ability to handle large transient disturbances) [1]. The feasible application of SM controllers for controlling power converters has recently been reported [2], [3]. However, it has been shown that SM controlled converters generally suffer from significant switching frequency variation when the input voltage and output load are varied [3], [4]. This complicates the design of the input and output filters. Obviously, designing the filters under a worst-case (lowest) frequency condition will result in oversized filters. Hence, it is more desirable to operate the converters at a constant switching frequency that does not deviate too far from its nominal value.

Basically, there are three possible approaches in keeping the switching frequency of the SM controller constant. One approach is to incorporate a constant ramp or timing function directly into the controller [3], [5], [6]. The main advantage of this approach is that the switching frequency is constant under all operating conditions, and can be easily controlled through varying the ramp/timing signal. However, due to the imposition of the ramp or timing function onto the SM switching function, the resulting converter system suffers from deteriorated transient response.

Manuscript received September 27, 2004; revised May 24, 2005. Recommended by Associate Editor B. Lehman.

The authors are with the Department of Electronic and Information Engineering, Hong Kong Polytechnic University, Hong Kong (e-mail: ensctan@eie.polyu.edu.hk).

Digital Object Identifier 10.1109/TPEL.2005.861191
The other approach is to employ pulse-width modulation (PWM) instead of hysteresis modulation (HM) [7], [8]. In practice, this is similar to classical PWM control schemes in which the control signal is compared to the ramp waveform to generate a discrete gate pulse signal [9]. The advantages are that it does not need additional hardware circuitries since the switching function is performed by the PWM modulator, and that its transient response is not deteriorated. However, implementation is nontrivial in order to preserve the original SM control law, especially when both current and voltage state variables are involved.

In this paper, we consider the third approach for alleviating the problem of switching frequency variation in the HM based controller. Specifically, we consider the use of some form of adaptive control to contain the switching frequency variation [10]. For line variation, we propose an adaptive feedforward control that varies the hysteresis band in the hysteresis modulator of the SM controller in the event of any change of the line input voltage [11]. For load variation, we propose an adaptive feedback controller that varies the control parameter (i.e., sliding coefficient) with the change of the output load.

In this paper, we will present a thorough investigation into the problem of switching frequency variation due to the deviation of operating conditions, and the effectiveness of the proposed solutions in alleviating the problem. In addition, methods of implementing the proposed adaptive control strategies are discussed in detail. Finally, experimental results will be presented for verification.

\section{REVIEW OF CONVENTIONAL SM CONTROLled CONVERTERS}

The system studied here is a buck converter controlled by a SM voltage mode controller, in which the state variables to be controlled are the output voltage error and the voltage error derivative (in phase canonic form). The theoretical model and analysis are summarized below. Details can be found in [4].

\section{A. Converter's Model}

Fig. 1 shows the schematic diagram of a sliding mode voltage controlled (SMVC) buck converter. Here, the voltage error $x_{1}$ and the voltage error dynamics (or the rate of change of voltage error) $x_{2}$ under continuous conduction mode (CCM) of operation can be expressed as

$$
\begin{aligned}
& x_{1}=V_{\text {ref }}-\beta V_{\mathrm{o}} \\
& x_{2}=\dot{x_{1}}=-\beta \frac{d V_{\mathrm{o}}}{d t}=\frac{\beta}{C}\left(\frac{V_{\mathrm{o}}}{R_{\mathrm{L}}}-\int \frac{u V_{\mathrm{i}}-V_{\mathrm{o}}}{L} d t\right)
\end{aligned}
$$




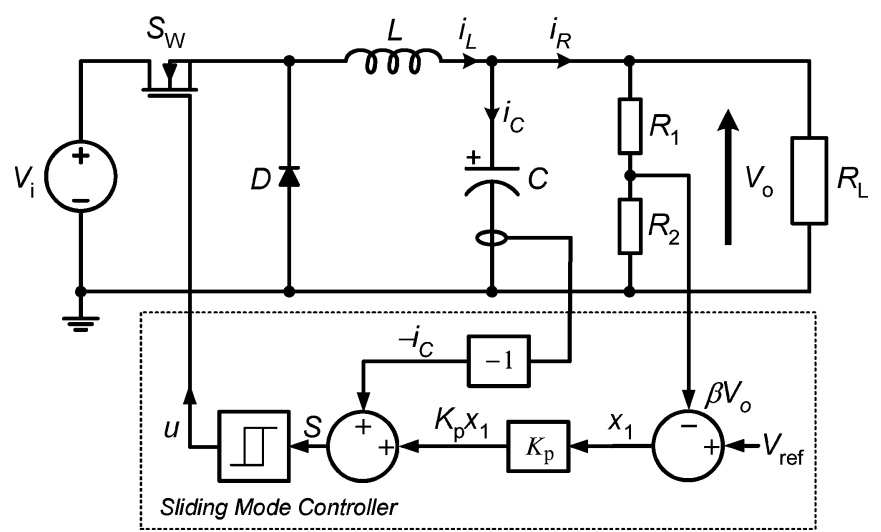

Fig. 1. Basic structure of an SMVC buck converter.

where $C, L, R_{\mathrm{L}}$ are the capacitance, inductance, and load resistance, respectively; $V_{\text {ref }}, V_{\mathrm{i}}$, and $\beta V_{\mathrm{o}}$ are the reference, input, and sensed output voltage respectively; $u=1$ or 0 is the switching state of power switch $S_{\mathrm{W}}$. Then, by differentiating (1) with respect to time, the state space model can be obtained as

$$
\left[\begin{array}{c}
\dot{x_{1}} \\
\dot{x_{2}}
\end{array}\right]=\left[\begin{array}{cc}
0 & 1 \\
-\frac{1}{L C} & -\frac{1}{R_{\mathrm{L} C}}
\end{array}\right]\left[\begin{array}{l}
x_{1} \\
x_{2}
\end{array}\right]+\left[\begin{array}{c}
0 \\
-\frac{\beta V_{\mathrm{i}}}{L C}
\end{array}\right] u+\left[\begin{array}{c}
0 \\
\frac{V_{\text {ref }}}{L C}
\end{array}\right] .
$$

\section{B. Controller's Model}

The SM voltage controller adopted in this study controls the state variables $x_{1}$ and $x_{2}$. Hence, the switching state $u$ can be determined from the control parameters $x_{1}$ and $x_{2}$ using the switching function

$$
u= \begin{cases}1={ }^{\prime} \mathrm{ON} & \text { when } S>\kappa \\ 0={ }^{\prime} \mathrm{OFF} & \text { when } S<-\kappa \\ \text { unchanged } & \text { otherwise }\end{cases}
$$

where control signal $S=\alpha x_{1}+x_{2}$, and the hysteresis bandwidth $\kappa$, is a fixed parameter that can be determined using the equation

$$
\kappa=\frac{V_{\mathrm{od}}\left(1-\frac{V_{\mathrm{od}}}{V_{\mathrm{i}(\mathrm{nom})}}\right)}{2 f_{\mathrm{Sd}} L}
$$

with $f_{\mathrm{Sd}}, V_{\mathrm{od}}$, and $V_{\mathrm{i}(\text { nom })}$ representing the desired steady-state switching frequency, the desired output voltage, and the nominal input voltage, respectively. It should be noted that the above equation is valid only if the sliding coefficient is set as $\alpha=$ $1 / R_{\mathrm{L}(\text { nom })} C$, and the converter is operating under the nominal load resistance $R_{\mathrm{L}(\text { nom) }}$. Otherwise, if $\alpha \neq 1 / R_{\mathrm{L}(\text { nom) }} C$ or that the load resistance differs from $R_{\mathrm{L}(\text { nom) }}$, the actual switching frequency will differ slightly from the desired frequency $f_{\mathrm{Sd}}$.

Furthermore, as previously discussed in [4], in terms of implementation, it is more practical to reconfigure the SM controller equation (by gain scaling $S$ by a factor of $C / \beta$ ) to the following form:

$$
S=K_{\mathrm{p}}\left(V_{\text {ref }}-\beta V_{\mathrm{o}}\right)-i_{C}
$$

where $K_{\mathrm{p}}=1 / \beta R_{\mathrm{L}(\mathrm{nom})}$ is a fixed gain parameter of the voltage error. It has also been shown in [4] that under this configuration, the conditions for SM control to exist are

$$
\left\{\begin{array}{l}
\lambda_{1}=\left(\frac{C}{\beta} \alpha-\frac{1}{\beta R_{\mathrm{L}}}\right) x_{2}-\frac{1}{\beta L} x_{1}+\frac{V_{\text {ref }}-\beta V_{\mathrm{i}}}{\beta L}<0 \\
\lambda_{2}=\left(\frac{C}{\beta} \alpha-\frac{1}{\beta R_{\mathrm{L}}}\right) x_{2}-\frac{1}{\beta L} x_{1}+\frac{V_{\text {ref }}}{\beta L}>0
\end{array} .\right.
$$

Now, considering that the converter is to operate at an input voltage range $V_{\mathrm{i}(\min )} \leq V_{\mathrm{i}} \leq V_{\mathrm{i}(\max )}$ and an output load resistance range $R_{\mathrm{L}(\min )} \leq R_{\mathrm{L}} \leq R_{\mathrm{L}(\max )}$, (6) can be rewritten as

$$
\left\{\begin{array}{l}
\frac{V_{\mathrm{od}}-V_{\mathrm{i}(\min )}}{L}<-\left(\alpha-\frac{1}{R_{\mathrm{L}(\max )} C}\right)\left|\hat{i_{C}}\right| \\
\frac{V_{\mathrm{od}}}{L}>\left(\alpha-\frac{1}{R_{\mathrm{L}(\max )} C}\right)\left|\hat{i_{C}}\right|
\end{array}\right.
$$

or more explicitly as

$$
\alpha< \begin{cases}\frac{V_{\mathrm{i}(\min )}-V_{\mathrm{od}}}{L\left|\hat{i}_{C}\right|}+\frac{1}{R_{\mathrm{L}(\max )} C} & \text { when } V_{\mathrm{i}(\min )}<2 V_{\mathrm{od}} \\ \frac{V_{\mathrm{od}}}{L\left|i_{C}\right|}+\frac{1}{R_{\mathrm{L}(\max )} C} & \text { otherwise }\end{cases}
$$

where $\hat{i_{C}}$ is the peak magnitude of the bidirectional capacitor current flow. Also, it should be noted that $\alpha$ must be positive to achieve system's stability. The proof is illustrated in [4].

\section{Problems Identification}

It is generally known that SM controllers using a hysteresis type of modulation suffer from frequency variation when operating conditions differ from their nominal conditions. Experimental evidence can be found in [4].

1) Experimental Observation: Fig. 2 shows the experimental data for the described converter system, with specifications as shown in Table I, operating under different input voltages $V_{\mathrm{i}}$ (left) and different load resistances $R_{\mathrm{L}}$ (right). It is observed that both the output voltage and switching frequency increase with increasing input voltage. These behaviors can be explained in terms of a general form of design (4), i.e.,

$$
f_{\mathrm{S}}=\frac{V_{\mathrm{o}}\left(1-\frac{V_{\mathrm{o}}}{V_{\mathrm{i}}}\right)}{2 \kappa L}
$$

which suggests that with preset design parameters, inductor $L$ and hysteresis band $\kappa$, and the assumption that output voltage is held at some constant value $V_{\mathrm{o}}$, a deviation in the actual input supply $V_{\mathrm{i}}$ will result in a change in the actual switching frequency $f_{\mathrm{S}}$. This in turn affects the regulation of the output voltage.

As for load variation, it is observed that switching frequency decreases while output voltage increases with increasing load resistance. This is because the change in switching frequency is caused by two components. First, the imperfect feedback loop causes a small steady-state error in the output voltage, i.e., $V_{\mathrm{o}} \neq$ $V_{\text {od }}$, which in turn causes small deviation of the switching frequency from its nominal value, i.e., $f_{\mathrm{S}} \neq f_{\mathrm{Sd}}$ [see (9)]. Hence, a change in load will lead to a small change in output voltage and consequently a small change in frequency. Second, in practice, the nominal load almost always differs from the operating load. As previously discussed, (4) and therefore (9), will not be strictly true if $\alpha \neq 1 / R_{\mathrm{L}(\text { nom })} C$ or the load resistance differs from $R_{\mathrm{L}(\mathrm{nom})}$. 




(a)

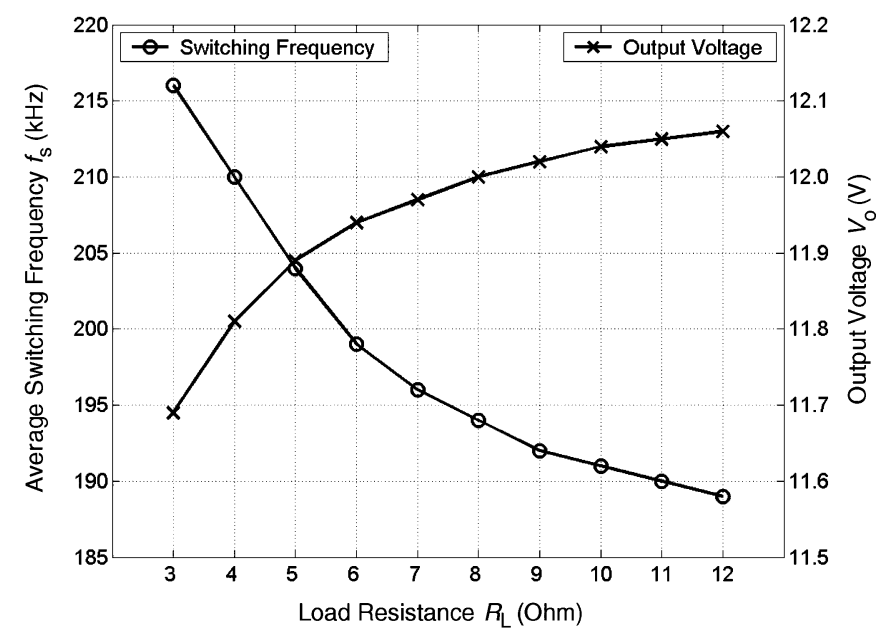

(b)

Fig. 2. Experimentally measured values of average switching frequency $\overline{f_{\mathrm{S}}}$ and average output voltage $\overline{V_{\mathrm{o}}}$ for (a) different input voltage $V_{\mathrm{i}}$ and (b) different load resistance $R_{\mathrm{L}}$.

TABLE I

SPECIFICATIONS OF BUCK CONVERTER

\begin{tabular}{|lcc|}
\hline Description & Parameter & Nominal Value \\
\hline Input voltage & $V_{\mathrm{i}(\text { nom })}$ & $24 \mathrm{~V}$ \\
Capacitance & $C$ & $100 \mu \mathrm{F}$ \\
Capacitor ESR & $r_{C}$ & $25 \mathrm{~m} \Omega$ \\
Inductance & $L$ & $110.23 \mu \mathrm{H}$ \\
Inductor resistance & $r_{L}$ & $144 \mathrm{~m} \Omega$ \\
Desired switching frequency & $f_{\mathrm{Sd}}$ & $200 \mathrm{kHz}$ \\
Load resistance & $R_{\mathrm{L}}$ & $6 \Omega$ \\
Desired output voltage & $V_{\mathrm{od}}$ & $12 \mathrm{~V}$ \\
\hline
\end{tabular}

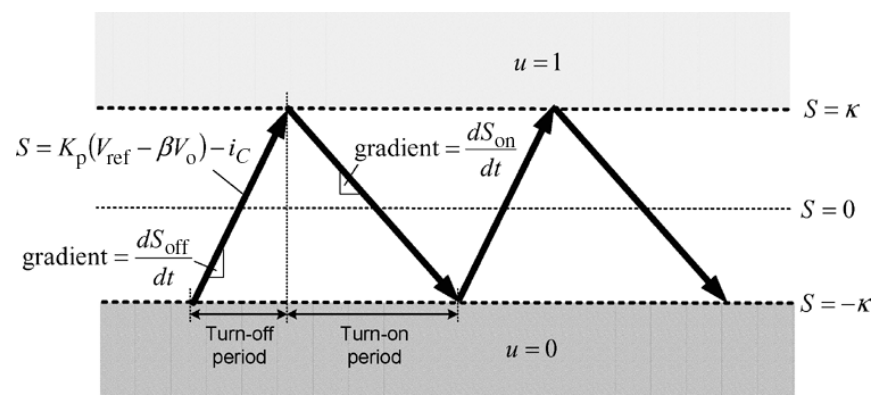

Fig. 3. Switching mechanism of the HM based SMVC buck converter.

2) Analytical Explanation: The controller operates according to (3) and (5), which may be graphically represented as shown in Fig. 3.

Here, the controller generates a turn-on signal $u=1$ if $S>\kappa$, and a turn-off signal $u=0$ if $S<-\kappa$. The parameter $S$ is a continuous signal computed using (5). By substituting $i_{C}=$ $i_{L}-i_{R}$, where $i_{L}$ and $i_{R}$ are, respectively, the inductor and load currents, $S$ can be expressed as

$$
S=K_{\mathrm{p}}\left(V_{\mathrm{ref}}-\beta V_{\mathrm{o}}\right)+\frac{V_{\mathrm{o}}}{R_{\mathrm{L}}}-\int \frac{u V_{\mathrm{i}}-V_{\mathrm{o}}}{L} d t .
$$

Close examination of this equation and the switching mechanism reveals that in the steady state, the terms $K_{\mathrm{p}}\left(V_{\mathrm{ref}}-\beta V_{\mathrm{o}}\right)$ and $V_{\mathrm{o}} / R_{\mathrm{L}}$, which contain only dc information, will cancel out the dc component of the term $\int\left(\left(u V_{\mathrm{i}}-V_{\mathrm{o}}\right) / L\right) d t$, leaving its ac component. This means that during steady-state operation, it is effectively the ac component of the term $\int\left(\left(u V_{\mathrm{i}}-V_{\mathrm{o}}\right) / L\right) d t$ that controls the behavior of the trajectory of $S$. Thus, only a change in $V_{\mathrm{o}}$ or $V_{\mathrm{i}}$ can affect the steady-state switching frequency.

Now, assume that $V_{\mathrm{o}}$ is constant. With $u=1$ (i.e., switch is turned on), if $V_{\mathrm{i}}$ is high, the gradient $d S_{\mathrm{on}} / d t$ will be high, and the turn-on period of the switch will be short. Conversely, if $V_{\mathrm{i}}$ is low, $d S_{\mathrm{on}} / d t$ will be low, and the turn-on period will be long. However, with $u=0$, the term $V_{\mathrm{i}}$ is nulled from the expression $\int\left(\left(u V_{\mathrm{i}}-V_{\mathrm{o}}\right) / L\right) d t$. Therefore, gradient $d S_{\text {off }} / d t$, i.e., the turn-off period is not affected by $V_{\mathrm{i}}$. Hence, it can be concluded that with increasing $V_{\mathrm{i}}$, turn-on period will be shorter, and considering that there is no change in the turn-off period, the switching frequency will be higher. Conversely, the switching frequency will be lower for smaller $V_{\mathrm{i}}$. Also, since the switching frequency does influence the magnitude of the steady-state output voltage error caused by the imperfect feedback loop, the output voltage is affected by line variation.

However, unlike $V_{\mathrm{i}}$ which has a direct control over the gradient of the trajectory of $S$, load $R_{\mathrm{L}}$ has an indirect and small influence over it. Although $R_{\mathrm{L}}$ appears in (10), it is important to recall that in steady state, the effective ac term in the expression $\int\left(\left(u V_{\mathrm{i}}-V_{\mathrm{o}}\right) / L\right) d t$ does not include $R_{\mathrm{L}}$. Hence, variation of $R_{\mathrm{L}}$ does not directly affect the trajectory of $S$. Instead, it is the steady-state error in the output voltage caused by the imperfect feedback loop, which depends on $R_{\mathrm{L}}$, that leads to the change in the gradient. It should be noted that in this case, both the turn-on and turn-off periods are influenced by $R_{\mathrm{L}}$. However, since the output voltage is well regulated, the change in its steady-state error will be small. This explains why load changes has only a small effect on the switching frequency. Specifically, as $R_{\mathrm{L}}$ increases, $V_{\mathrm{o}}$ will increase, the gradient of trajectory of $S$ will decrease, and the frequency will decrease [see (4)].

\section{Possible Solutions}

As mentioned earlier, there are three possible approaches to alleviating the problem of frequency variation caused by line and load variations. The simplest approach is to fix the switching 


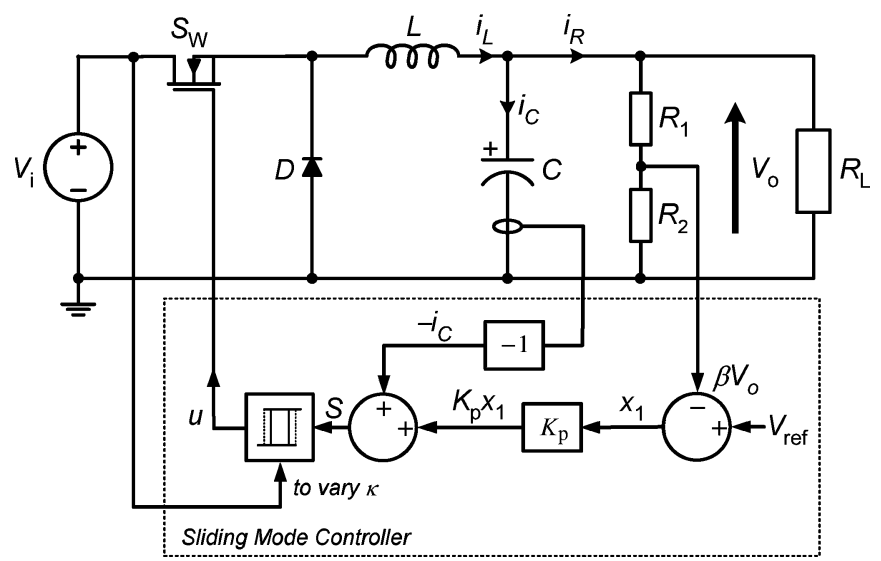

Fig. 4. Basic structure of an adaptive feedforward SMVC buck converter.

frequency by incorporating a constant ramp or timing function directly into the controller [3], [5], [7], [8], for example, by superimposing a constant ramp signal into switching function [3]; or by including a constant switching frequency circuit in the switching function [5]. Despite their simplicity, realization methods in this approach suffers from deteriorated transient response. The second approach is by replacing the HM with PWM [7], [8]. However, this approach is not always implementable for some SM controller types.

Hence, it may be better to consider an alternative approach to solving this problem. Our proposed approach is to incorporate some form of adaptive control into the HM based SM controller. Although the idea has been previously mentioned in [4], [10], it has not been seriously investigated. The remaining sections of this paper will describe the adaptive control strategies, their means of implementation, and the major results and conclusions.

\section{AdAPTIVE FEEDFORWARD CONTROL SCHEME}

\section{A. Theory}

To keep the switching frequency fixed against line variation, we introduce an adaptive feedforward control scheme that varies the hysteresis band in the hysteresis modulator of the SM controller in the event of any change of the line input voltage. Fig. 4 shows the basic structure of the adaptive feedforward SMVC buck converter.

The operation of the adaptive feedforward variable hysteresis band is illustrated in Fig. 5, which shows the trajectory of $S$ for one switching cycle of the steady-state operation. Here, the terms $S_{\text {off(min) }}$ and $S_{\text {on(min) }}$ represent the trajectory of $S$ when the input voltage is minimum, for, respectively, the turn-off period $T_{\text {off(min) }}$ and turn-on period $T_{\text {on(min) }}$. Similarly, $S_{\text {off(max) }}$ and $S_{\text {on(max) }}$ represent the trajectory of $S$ when the input voltage is maximum, for, respectively, the turn-off period $T_{\text {off(max) }}$ and turn-on period $T_{\text {on(max) }}$. Also, $\kappa_{\min }$ and $\kappa_{\max }$ represent the required hysteresis bandwidth for maintaining the same switching frequency at minimum and maximum input voltage. Recall that when $u=0, V_{\mathrm{i}}$ does not affect the gradient of trajectory $S$. Hence, the gradient of trajectory $S_{\text {off(min) }}$ and that of trajectory $S_{\text {off(max) }}$ are equivalent. But when $u=1$, the gradient of trajectory $S_{\text {off(min) }}$ will be smaller than that

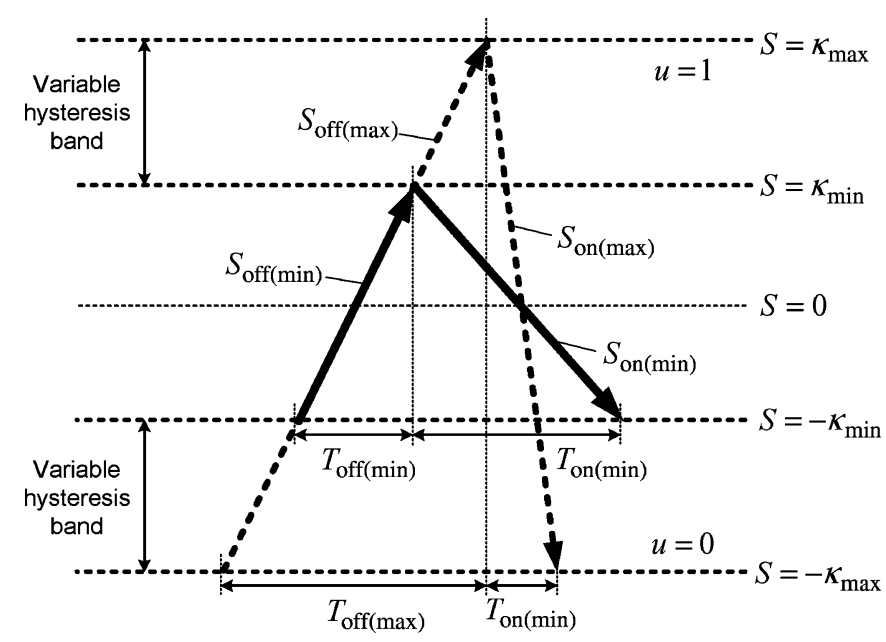

Fig. 5. Operating mechanism of the adaptive feedforward variable hysteresis band.

of trajectory $S_{\text {off(max) }}$. Therefore, it is possible to obtain a hysteresis bandwidth $\kappa_{\max }$ that produces a switching time period $T_{\max }=T_{\text {off }(\max )}+T_{\text {on(max) }}$ when the input voltage is maximum, and is equivalent to the switching time period $T_{\min }=T_{\text {off }(\min )}+T_{\text {on(min) }}$ that employs the hysteresis bandwidth $\kappa_{\min }$ when the input voltage is minimum. Finally, the input voltage is sensed and the hysteresis bandwidth is adjusted accordingly to maintain a certain desired switching frequency.

The real-time computation of the hysteresis bandwidth for different input voltages can be performed using a general form of (4), where the input voltage term is now $V_{\mathrm{i}}$, instead of $V_{\mathrm{i}(\mathrm{nom})}$, i.e.,

$$
\kappa=\frac{V_{\text {od }}\left(1-\frac{V_{\text {od }}}{V_{\mathrm{i}}}\right)}{2 f_{\mathrm{Sd}} L} .
$$

Simulation $^{1}$ has been performed to verify the idea. Fig. 6 shows the simulated data for the SMVC buck converter, with and without incorporating the adaptive feedforward control scheme. It can be seen that the adoption of the adaptive feedforward control scheme reduces the variation of $\bar{f}_{\mathrm{S}}$ for the input voltage range $18 \mathrm{~V} \leq V_{\mathrm{i}} \leq 30 \mathrm{~V}$ from $\pm 35 \%$ to within $\pm 5 \%$ of $f_{\mathrm{sd}}(200 \mathrm{kHz})$.

\section{B. Implementation Method}

Several methods of varying the hysteresis band of the hysteresis modulator are possible. In the case of employing the Schmitt trigger as the hysteresis modulator, the hysteresis band can be adjusted by changing the resistor gain ratio $R_{\mathrm{ST} 2} / R_{\mathrm{ST} 1}$, or by adjusting the power supply $V_{\mathrm{CC}}^{+} / V_{\mathrm{CC}}^{-}$. In this work, the latter option is chosen.

Fig. 7 shows the schematic of the noninverting Schmitt Trigger used in our implementation. The hysteresis bandwidth of this circuit is

$$
2 \kappa=\frac{R_{\mathrm{ST} 1}}{R_{\mathrm{ST} 2}}\left(V_{\mathrm{CC}}^{+}-V_{\mathrm{CC}}^{-}\right) .
$$

${ }^{1}$ The simulation is performed using Matlab/Simulink. The step size taken for all simulations is $10 \mathrm{~ns}$ 


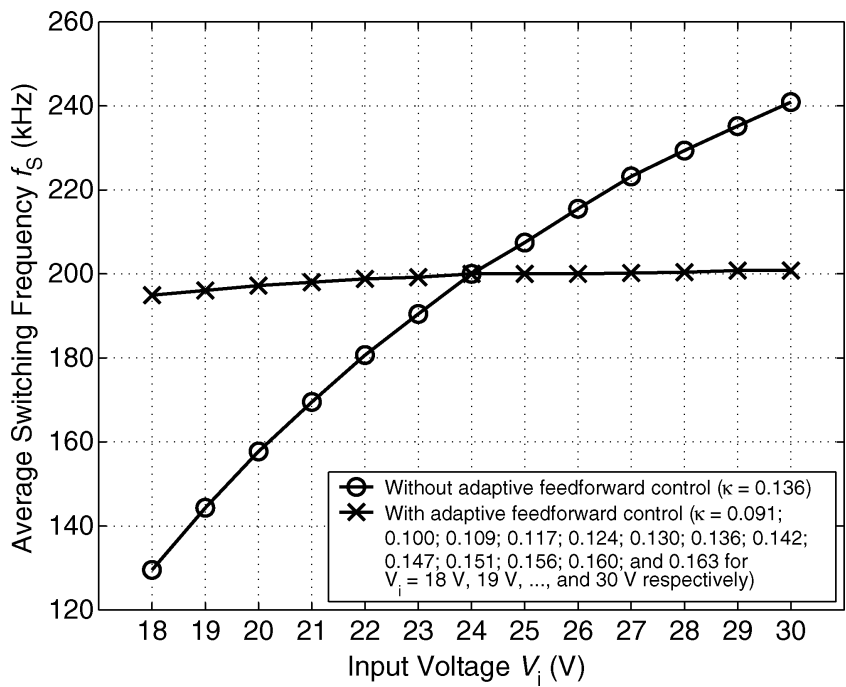

Fig. 6. Simulated data of average switching frequency $\bar{f}_{\mathrm{S}}$ of the SMVC buck converter, with and without the incorporation of the adaptive feedforward control scheme, operating under line variation with input voltages $18 \mathrm{~V} \leq V_{\mathrm{i}} \leq$ $30 \mathrm{~V}$ and at $R_{\mathrm{L}}=6 \Omega$.

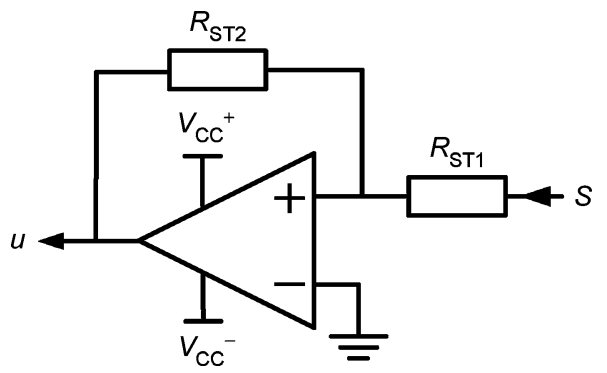

Fig. 7. Schematic of a standard noninverting Schmitt trigger circuit.

Equating with (11) gives

$$
V_{\mathrm{CC}}^{+}-V_{\mathrm{CC}}^{-}=\frac{R_{\mathrm{ST} 2}}{R_{\mathrm{ST} 1}} \frac{V_{\mathrm{od}}}{f_{\mathrm{Sd}} L}\left[1-\frac{V_{\mathrm{od}}}{V_{\mathrm{i}}}\right] .
$$

Also, $V_{\mathrm{CC}}^{+}$and $V_{\mathrm{CC}}^{-}$should be

$$
\begin{aligned}
& V_{\mathrm{CC}}^{+}=\frac{1}{2} G_{S}\left[1-\frac{V_{\mathrm{od}}}{V_{\mathrm{i}}}\right] \\
& V_{\mathrm{CC}}^{-}=-\frac{1}{2} G_{S}\left[1-\frac{V_{\mathrm{od}}}{V_{\mathrm{i}}}\right]
\end{aligned}
$$

where $G_{S}=\left(R_{\mathrm{ST} 2} / R_{\mathrm{ST} 1}\right)\left(V_{\mathrm{od}} / f_{\mathrm{Sd}} L\right)$. In practice, this variable power supply, $V_{\mathrm{CC}}^{+} / V_{\mathrm{CC}}^{-}$, can be obtained through simple analog computation (see Fig. 8).

\section{AdAPTIVE FEEDBACK CONTROL Scheme}

\section{A. Theory}

The problem of variable switching frequency as load varies is caused by the difference between the operating load resistance and the nominal load resistance used in the controller design, i.e., $R_{\mathrm{L}} \neq R_{\mathrm{L}(\text { nom) }}$. When this occurs, (4), which assumes that the sliding coefficient is chosen as $\alpha=1 / R_{\mathrm{L}(\text { nom) }} C$ and that the converter is operating with the nominal load resistance $R_{\mathrm{L}(\mathrm{nom})}$, becomes invalid [4]. This results in the deviation of

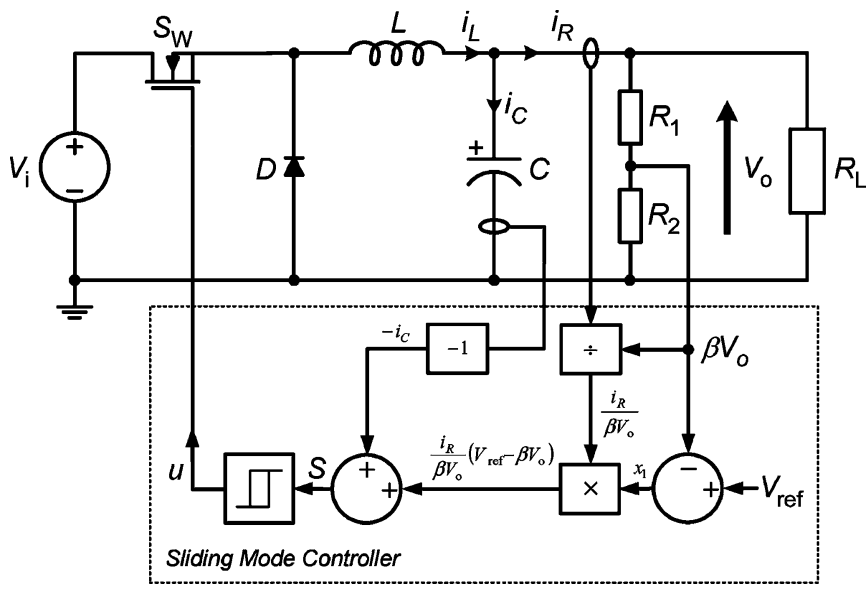

Fig. 8. Basic structure of an adaptive feedback SMVC buck converter.

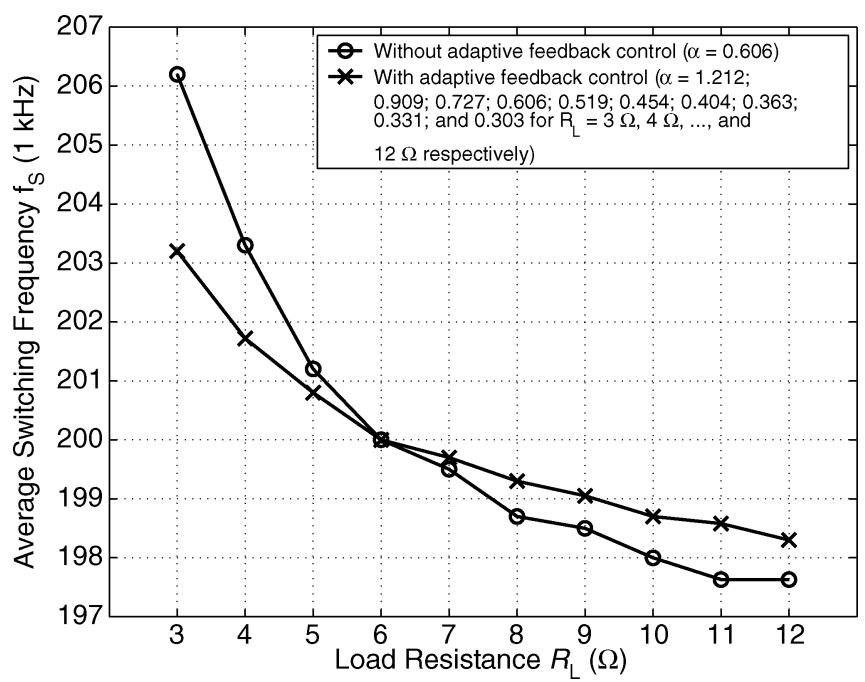

Fig. 9. Simulated data of average switching frequency $\bar{f}_{S}$ of the SMVC buck converter, with and without the incorporation of the adaptive feedback control scheme, operating under load variation with load resistances $3 \Omega \leq R_{\mathrm{L}} \leq 12 \Omega$ and at $V_{\mathrm{i}}=24 \mathrm{~V}$.

the switching frequency from the nominal value. Thus, a logical solution is to ensure that (4) is valid for all operating conditions. This can be accomplished by making the sliding coefficient adaptive. Instead of simply fixing it at $\alpha=1 / R_{\mathrm{L}(\text { nom })} C$, the sliding coefficient is designed to be load dependent: $\alpha=$ $1 / R_{\mathrm{L}} C$, i.e., a change in the operating load resistance $R_{\mathrm{L}}$ will immediately change $\alpha$. Such a system has been proposed in [12] to improve system's performances. Here, it is suggested as a means to also maintain the validity of (9) so that $f_{\mathrm{S}}$ becomes independent of $R_{\mathrm{L}}$. Hence, the effect of frequency variation caused by the mismatch between the nominal and the operating load is alleviated. Note that although the convergency rate of the system is affected by the adaptive feedback control, its stability is preserved since $\alpha>0$.

Fig. 9 shows the simulated data for the SMVC buck converter, with and without the incorporation of the adaptive feedback control scheme. It can be seen that the adoption of the adaptive feedback control scheme reduces the variation of $\bar{f}_{\mathrm{S}}$ for the load resistance range $3 \Omega \leq R_{\mathrm{L}} \leq 12 \Omega$ from \pm 3.1 to within $\pm 1.6 \%$ of $f_{\mathrm{sd}}(200 \mathrm{kHz})$. 


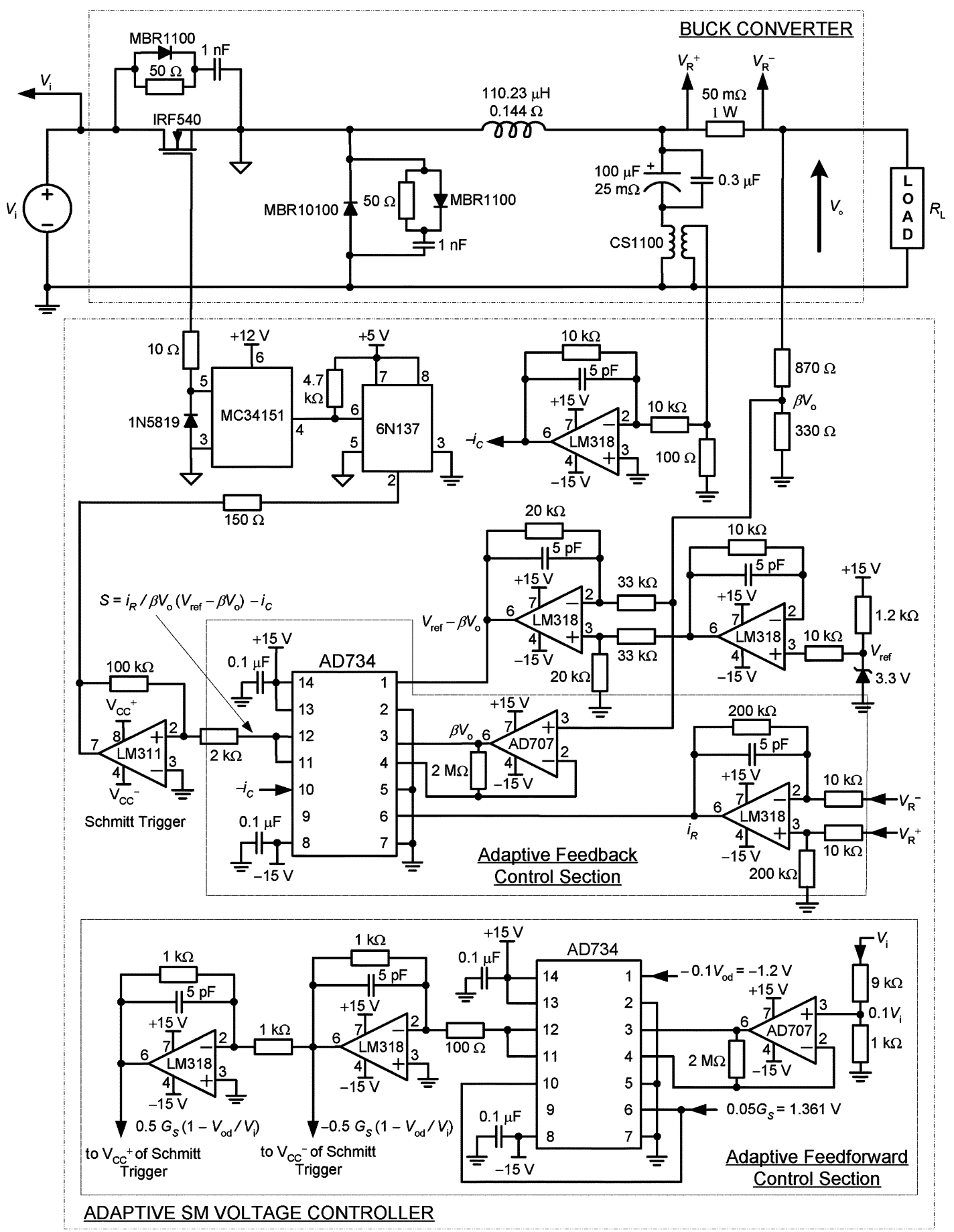

Fig. 10. Full schematic diagram of the adaptive SMVC buck converter prototype.

\section{B. Implementation Method}

By making the sliding coefficient adaptive, i.e., $\alpha=1 / R_{\mathrm{L}} C$, SM control equation (10) becomes

$$
S=\frac{1}{\beta R_{\mathrm{L}}}\left(V_{\text {ref }}-\beta V_{\mathrm{o}}\right)-i_{C}
$$

Clearly, the computation of the control signal $S$ requires the measurement of all involving variables in the equation. How- ever, since it is not possible to measure resistance directly, the relationship

$$
R_{\mathrm{L}}=\frac{V_{\mathrm{o}}}{i_{\mathrm{R}}}
$$

is exploited to obtain the instantaneous loading resistance. Hence, the adaptive feedback control scheme is practically implemented using

$$
S=\frac{i_{R}}{\beta V_{\mathrm{o}}}\left(V_{\text {ref }}-\beta V_{\mathrm{o}}\right)-i_{C} \quad \text { where } V_{\mathrm{o}} \neq 0 .
$$




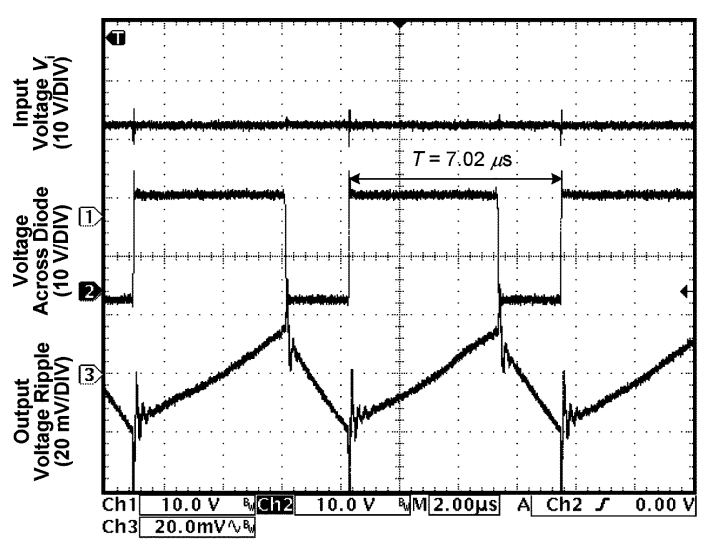

(a)

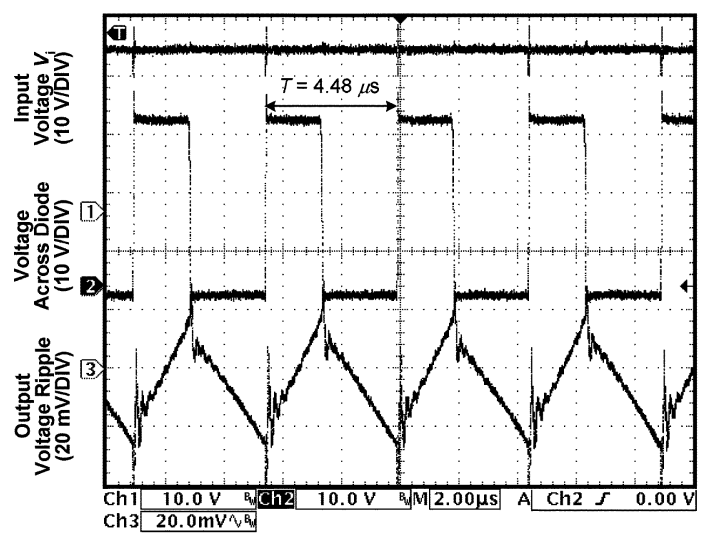

(c)

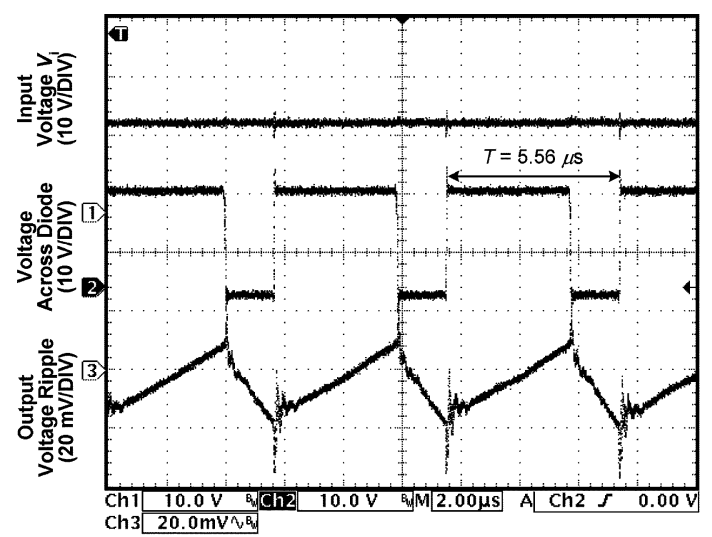

(b)

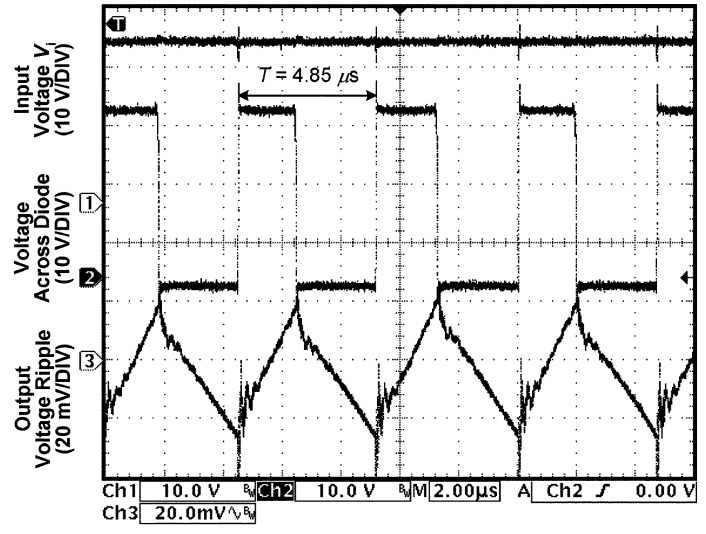

(d)

Fig. 11. Experimental waveforms of input voltage $V_{\mathrm{i}}$, voltage across freewheeling diode $D$, and output voltage ripple $\widetilde{V_{\mathrm{o}}}$ of the SMVC converter that is operating at input voltage (a) $V_{\mathrm{i}}=18 \mathrm{~V}$ (without adaptive feedforward control), (b) $V_{\mathrm{i}}=18 \mathrm{~V}$ (with adaptive feedforward control), (c) $V_{\mathrm{i}}=30 \mathrm{~V}$ (without adaptive feedforward control), and (d) $V_{\mathrm{i}}=30 \mathrm{~V}$ (with adaptive feedforward control), under nominal load resistance $R_{\mathrm{L}}=6 \Omega$.

With this arrangement, the monitoring of instantaneous $i_{R}$ and $V_{\mathrm{O}}$ allows information of the instantaneous $R_{\mathrm{L}}$ to be known. By absorbing this information into the control scheme, an adaptive feedback SM voltage controller, which basically varies $\alpha$ according to $R_{\mathrm{L}}$, is obtained. Note also that $V_{\mathrm{o}} \neq 0$, which otherwise causes a division by zero problem. In case of an analog implementation of this equation, a divider that saturates the computation signal at zero division may be used.

\section{EXPERIMENTAL RESULTS AND DISCUSSIONS}

To verify the proposed adaptive feedforward and adaptive feedback control strategies, an experimental prototype has been constructed with specifications as shown in Table I. Fig. 10 shows the full schematic diagram of the proposed converter and controller. Separate tests are performed to evaluate the performance of the adaptive controllers with respect to line regulation and load regulation.

\section{A. Line Variation}

Fig. 11(a)-(d) shows the experimental waveforms of the converter system at minimum and maximum input voltages, for the SM controller with and without using the adaptive feedforward control scheme. It can be easily observed that for both the cases $V_{\mathrm{i}}=18 \mathrm{~V}$ and $V_{\mathrm{i}}=30 \mathrm{~V}$, with the same input voltage, the



Fig. 12. Experimentally measured average switching frequency $\bar{f}_{\mathrm{S}}$ of the SMVC buck converter, with and without the incorporation of the adaptive feedforward control scheme, operating under line variation with input voltages $18 \mathrm{~V} \leq V_{\mathrm{i}} \leq 30 \mathrm{~V}$ and at $R_{\mathrm{L}}=6 \Omega$.

system with the adaptive feedforward control has switching period much closer to the desired switching period $T=5 \mu \mathrm{s}$. A plot of the measured average switching frequency versus different input voltages is shown in Fig. 12. The experimental data 


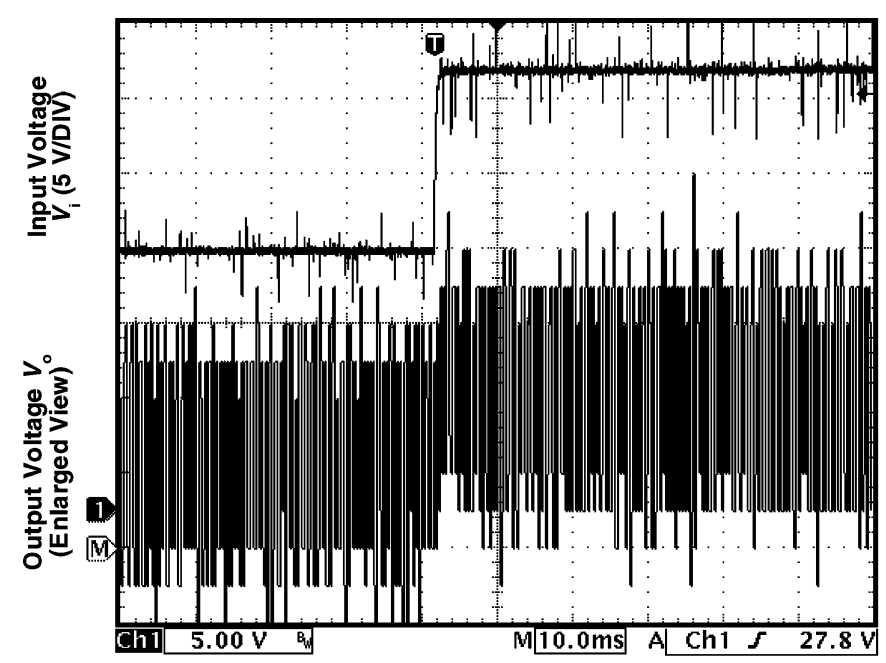

(a)

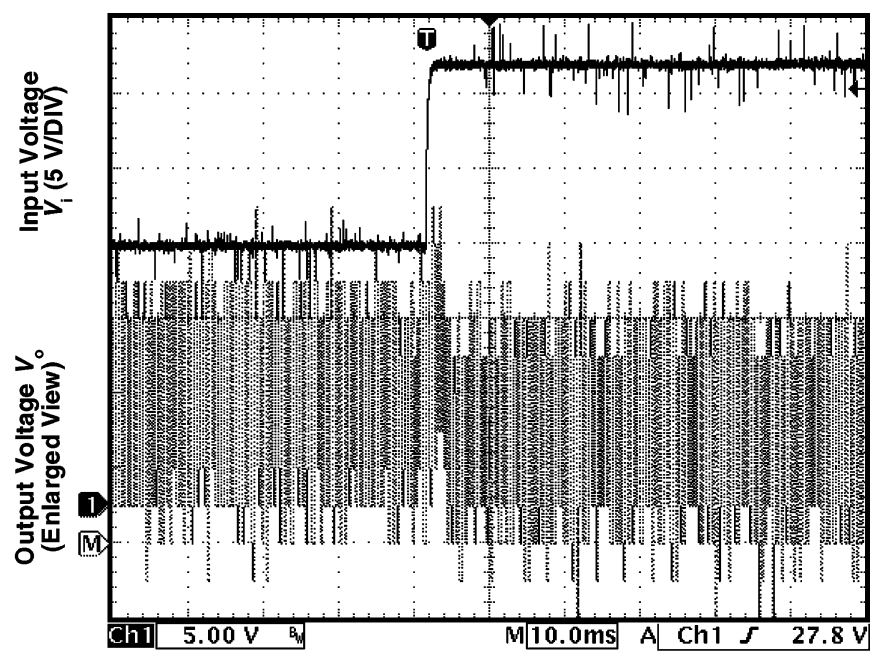

(b)

Fig. 13. Experimental waveforms of input voltage $V_{\mathrm{i}}$ and enlarged view of output voltage $V_{\mathrm{o}}$ of the SMVC buck converter (a) without adaptive feedforward control and (b) with adaptive feedforward control, operating at step input voltage change from $V_{\mathrm{i}}=18 \mathrm{~V}$ to $V_{\mathrm{i}}=30 \mathrm{~V}$, and at $R_{\mathrm{L}}=6 \Omega$.

confirms more conclusively the capability of the adaptive feedforward control scheme in reducing the variation of $\bar{f}_{\mathrm{S}}$. For the input voltage range $18 \mathrm{~V} \leq V_{\mathrm{i}} \leq 30 \mathrm{~V}$, the frequency variation is reduced from $\pm 28.8 \%$ to within $\pm 10.0 \%$ of $f_{\text {sd }}$. The improvement is less than the one obtained from simulation as shown in Fig. 6, which reduces the variation for the same input voltage range from $\pm 35 \%$ to within $\pm 5 \%$ of $f_{\text {sd }}$. The deterioration is caused by practical components' variations and delay times. These factors are not modeled in the simulation program.

Fig. 13(a) and (b) shows the experimental waveforms of the converter system to which a step change of input voltage from minimum to maximum is applied. For the converter without the adaptive feedforward control, the enlarged view of the output voltage indicates that there is an upward dc shift when the input voltage steps up to a higher value. As explained earlier, this is due to the change in switching frequency, which increases or decreases the magnitude of the steady-state output voltage error caused by the imperfect feedback loop. Hence, for the converter with the adaptive feedforward control where the switching frequency variation is much reduced, there is less dc shift in the output voltage associated with the step change. This situation is experimentally captured and illustrated in Fig. 14. For the input voltage range $18 \mathrm{~V} \leq V_{\mathrm{i}} \leq 30 \mathrm{~V}$, the line regulation is improved from $1.59 \%$ of $V_{\mathrm{o}\left(\mathrm{V}_{\mathrm{i}}=24 \mathrm{~V}\right)}$ to $0.17 \%$ of $V_{\mathrm{o}\left(\mathrm{V}_{\mathrm{i}}=24 \mathrm{~V}\right)}$ through the adaptive feedforward control scheme.

Fig. 15(a) and (b) show the output voltage ripple waveforms of the converter operating at nominal load when $V_{\mathrm{i}}$ is sinusoidally varied from $20.9 \mathrm{~V}$ to $27.1 \mathrm{~V}$ at a frequency of $100 \mathrm{~Hz}$. The aim is to test the robustness of the converter against a slowly varying input voltage. Without the adaptive feedforward control, the maximum peak-to-peak output voltage is around $80 \mathrm{mV}$, i.e., the input voltage ripple rejection is $-37.81 \mathrm{~dB}$ at $100 \mathrm{~Hz}$. With the adaptive feedforward control, the maximum peak-to-peak output voltage is around $200 \mathrm{mV}$, i.e., the input voltage ripple rejection is $-29.85 \mathrm{~dB}$ at $100 \mathrm{~Hz}$. The slight deterioration in the audio susceptibility performance illustrates the main tradeoff in using the adaptive feedforward control scheme. Yet, in both

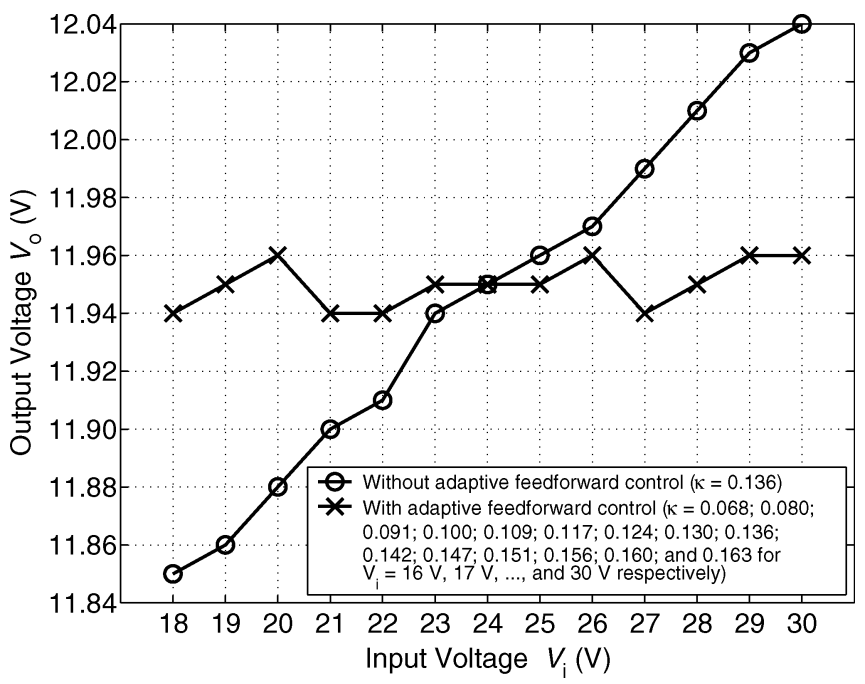

Fig. 14. Experimentally measured output voltage $V_{\circ}$ of the SMVC buck converter, with and without the incorporation of the adaptive feedforward control scheme, operating under line variation with input voltages $18 \mathrm{~V}$ $\leq V_{\mathrm{i}} \leq 30 \mathrm{~V}$ and at $R_{\mathrm{L}}=6 \Omega$.

cases, the converter still has an adequate audio susceptibility performance.

It is worth noting that the output voltage varies twice as fast as the line variation. Without the adaptive feedforward control, the output voltage varies at the same frequency as the input voltage, i.e., $100 \mathrm{~Hz}$. However, with the adaptive feedforward control, the output voltage varies at twice the frequency of the input voltage, i.e., $200 \mathrm{~Hz}$. This can be explained by inspecting (9): $f_{\mathrm{S}}=V_{\mathrm{o}}\left(1-\left(V_{\mathrm{o}} / V_{\mathrm{i}}\right)\right) / 2 \kappa L$. Without adaptive control, since $\kappa$ is kept constant and $f_{\mathrm{S}}$ is varying with the change of input voltage $V_{\mathrm{i}}$, both $f_{\mathrm{S}}$ and $V_{\mathrm{o}}$ vary at the same frequency as $V_{\mathrm{i}}$. With the adaptive control, $\kappa$ varies sinusoidally at $100 \mathrm{~Hz}$. Since the adaptive control cannot fully eliminate the frequency variation due to line variation, $f_{\mathrm{S}}$ will also vary sinusoidally at $100 \mathrm{~Hz}$. Hence, $V_{\mathrm{o}}$ will vary according to the product of $\kappa$ and $f_{\mathrm{S}}$, i.e., $\sin ^{2} 2 \pi 100 t \Rightarrow \cos 2 \pi 200 t$. 


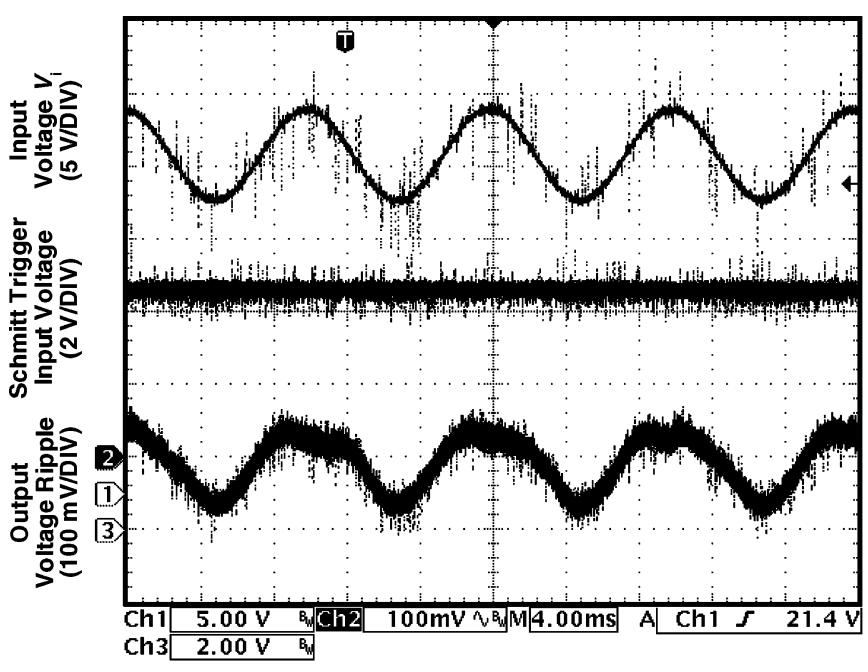

(a)

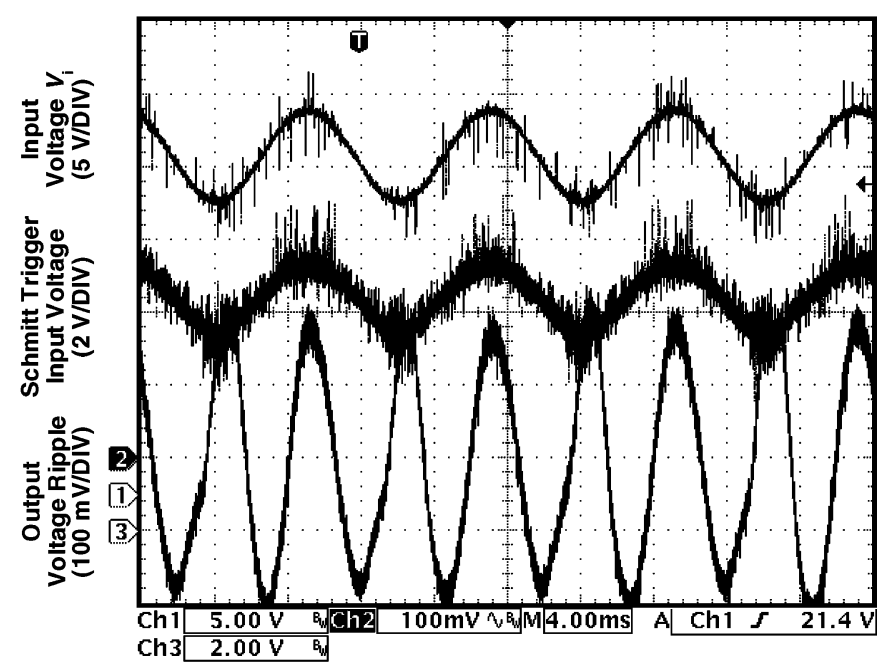

(b)

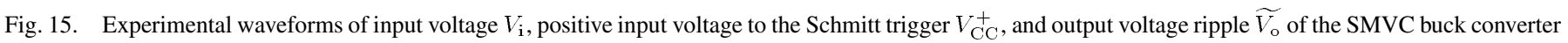

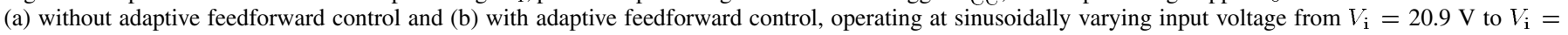
$27.1 \mathrm{~V}$, and at $R_{\mathrm{L}}=6 \Omega$.



Fig. 16. Experimentally measured average switching frequency $\bar{f}_{\mathrm{S}}$ of the SMVC buck converter, with and without the incorporation of the adaptive feedback control scheme, operating under load variation with load resistances $3 \Omega \leq R_{\mathrm{L}} \leq 12 \Omega$ and at $V_{\mathrm{i}}=24 \mathrm{~V}$.

\section{B. Load Variation}

Figs. 16 and 17 show the experimental data of the converter system at different load resistances for the SM controller with and without the adaptive feedback control scheme. From Fig. 16, it can be seen that with the adaptive feedback control, the variation of switching frequency with respect to load resistance improves from an average of $d \overline{f_{\mathrm{S}}} / d R_{\mathrm{L}}=-3.0 \mathrm{kHz} / \Omega$ (without adaptive feedback control) to an average of $d \overline{f_{\mathrm{S}}} / d R_{\mathrm{L}}=-2.1 \mathrm{kHz} / \Omega$ (with adaptive feedback control). Thus, for the load resistance range $3 \Omega \leq R_{\mathrm{L}} \leq 12 \Omega$, the frequency variation has been reduced from $\pm 8.5 \%$ to within $\pm 6.0 \%$ of $f_{\text {sd }}$. This verifies the capability of the adaptive feedback control scheme in suppressing the variation of switching frequency caused by load variation. Furthermore, it should be pointed out that the quantitative



Fig. 17. Experimentally measured output voltage $V_{\mathrm{o}}$ of the SMVC buck converter, with and without the incorporation of the adaptive feedback control scheme, operating under load variation with load resistances $3 \Omega \leq R_{\mathrm{L}} \leq 12 \Omega$ and at $V_{\mathrm{i}}=24 \mathrm{~V}$.

difference between the results obtained from the experiment and the simulation in Fig. 9 is due to practical components' variations and delay times that are not modeled in the simulation program.

The reduction in the switching frequency variation with the adaptive feedback control is predictably the outcome of better performance in the load regulation. This has been explained earlier and can be observed from Fig. 17. Without the adaptive feedback control, there is a $0.37-\mathrm{V}$ deviation (i.e., $3.1 \%$ of $V_{\mathrm{o} \text { (nominal load) }}$ ) in $V_{\mathrm{o}}$ for the entire load range, i.e., load regulation $d V_{\mathrm{O}} / d R_{\mathrm{L}}$ averages at $0.040 \mathrm{~V} / \Omega$. With the adaptive feedback control, there is a $-0.23 \mathrm{~V}$ deviation (i.e., $-1.9 \%$ of $V_{\mathrm{o} \text { (nominal load) }}$ ) in $V_{\mathrm{o}}$ for the entire load range, i.e., load regulation $d V_{\mathrm{o}} / d R_{\mathrm{L}}$ averages at $-0.026 \mathrm{~V} / \Omega$. Noticeably, the incorporation of the adaptive feedback control scheme has 


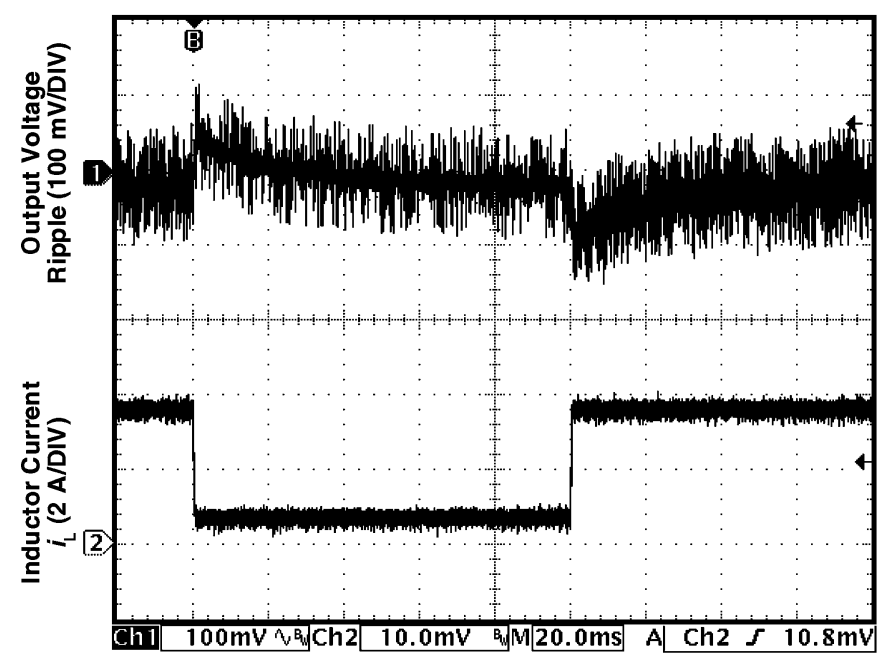

(a)



(b)

Fig. 18. Experimental waveforms of output voltage ripple $\widetilde{V_{\mathrm{o}}}$ and inductor current $i_{\mathrm{L}}$ of the SMVC buck converter (a) without adaptive feedback control and (b) with adaptive feedback control, operating at $V_{\mathrm{i}}=24 \mathrm{~V}$ and step load changes that alternates between $R_{\mathrm{L}}=12 \Omega$ and $R_{\mathrm{L}}=3 \Omega$.

changed the way in which the output voltage is regulated. This is evident from the fact that the output voltage without the adaptive feedback control increases with increasing resistance whereas output voltage with the adaptive feedback control decreases with increasing resistance. Note that we are varying $\alpha$ as the load changes. Since $\alpha$ is effectively the dc gain parameter in the controller, it is actually controlling the steady-state output voltage. Thus, when the load resistance increases, the output voltage of the converter (without adaptive feedback control) should supposedly increase, and its switching frequency should drop below the nominal value. However, when $\alpha$ is adaptive (with the adaptive feedback control) and could react to the increment in the load resistance, it actually decreases, causing the output voltage to decrease. The switching frequency thus increases accordingly.

Fig. 18(a) and (b) show the output waveforms of the operation with load resistance that alternates between $R_{\mathrm{L}}=12 \Omega$ and $R_{\mathrm{L}}=3 \Omega$. The comparison shows that the incorporation of the adaptive feedback control scheme will have little effect on the transient performance. Specifically, the overshoot voltage ripple is increased from $120 \mathrm{mV}$ (without adaptive feedback) to $180 \mathrm{mV}$ (with adaptive feedback), and the settling time from 60 to $70 \mathrm{~ms}$.

Remarks: In our case studies, the ability of the adaptive feedback control scheme to reduce the switching frequency variation is seemingly insignificant as compared to the adaptive feedforward control scheme. However, recalling that the switching frequency variations are much larger for larger load variations, the ability of the adaptive feedback control scheme to suppress variations in such circumstance, will be better appreciated. Moreover, the inclusion of the adaptive feedback control scheme also constitutes a significant improvement in the load regulation of the converter, which is also an important aspect of its application. Yet, considering that the employment of the scheme requires additional circuitries and a current sensor, which adds more complexity to the SM controller, the decision for its adoption in converter control is therefore application specific.

\section{CONCLUSION}

We have investigated to some depth the problem of switching frequency variation in the SM controlled dc/dc converter. Our discussion has focused on the circuit operation. We have also proposed practical solutions to the problem of switching frequency variation and discussed in detail the implementation methods. The effectiveness of our proposed solutions have been verified by experiments. In conclusion, we have found that simple adaptive schemes can be applied to SM controllers for eliminating frequency variation and hence provide more practical means of implementing SM controller for dc/dc converters.

\section{ACKNOWLEDGMENT}

The authors would like to thank Y. L. Cheng for help in developing the experimental prototype.

\section{REFERENCES}

[1] V. Utkin, J. Guldner, and J. X. Shi, Sliding Mode Control in Electromechanical Systems. London, U.K.: Taylor and Francis, 1999.

[2] R. Venkataramanan, A. Sabanoivc, and S. Ćuk, "Sliding mode control of DC-to-DC converters," in Proc. IEEE Conf. Industrial Electronics, Control Instrumentations (IECON), 1985, pp. 251-258.

[3] P. Mattavelli, L. Rossetto, G. Spiazzi, and P. Tenti, "General-purpose sliding-mode controller for dc/dc converter applications," in Proc. IEEE PESC, Jun. 1993, pp. 609-615.

[4] S. C. Tan, Y. M. Lai, M. K. H. Cheung, and C. K. Tse, "On the practical design of a sliding mode voltage controlled buck converter," IEEE Trans. Power Electron., vol. 20, no. 2, pp. 425-437, Mar. 2005.

[5] B. J. Cardoso, A. F. Moreira, B. R. Menezes, and P. C. Cortizo, "Analysis of switching frequency reduction methods applied to sliding mode controlled dc/dc converters," in Proc. IEEE Applied Power Electronics Conf. Expo (APEC), Feb. 1992, pp. 403-410.

[6] L. Iannelli and F. Vasca, "Dithering for sliding mode control of DC/DC converters," in Proc. IEEE PESC'04, Jun. 2004, pp. 1616-1620.

[7] V. M. Nguyen and C. Q. Lee, "Indirect implementations of sliding-mode control law in buck-type converters," in Proc. IEEE Applied Power Electronics Conf. Expo. (APEC), vol. 1, Mar. 1996, pp. 111-115.

[8] S. C. Tan, Y. M. Lai, C. K. Tse, and M. K. H. Cheung, "A pulse-widthmodulation based sliding mode controller for buck converters," in Proc. IEEE PESC'04, Jun. 2004, pp. 3647-3653. 
[9] D. M. Mitchell, DC/DC Switching Regulator Analysis. New York: McGraw Hill, 1998.

[10] V. M. Nguyen and C. Q. Lee, "Tracking control of buck converter using sliding-mode with adaptive hysteresis," in Proc. IEEE PESC, vol. 2, Jun. 1995, pp. 1086-1093.

[11] Q. Yao and D. G. Holmes, "A simple, novel method for variable-hysteresis-band current control of a three phase inverter with constant switching frequency," in Proc. IEEE Industry Applications Soc. Annu. Meeting, vol. 2, Oct. 1993, pp. 1122-1129.

[12] S. C. Tan, Y. M. Lai, M. K. H. Cheung, and C. K. Tse, "An adaptive sliding mode controller for buck converter in continuous conduction mode," in Proc. IEEE Applied Power Electronics Conf. Expo (APEC), Feb. 2004, pp. 1395-1400.

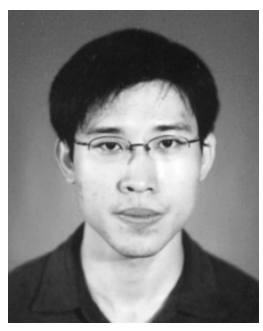

Siew-Chong Tan (S'00-M'06) received the B.Eng.(with honors) and M.Eng. degrees in electrical and computer engineering from the National University of Singapore, Singapore, in 2000 and 2002, respectively, and the Ph.D. degree from the Hong Kong Polytechnic University, Hong Kong, in 2005.

He is currently a Research Associate with the Hong Kong Polytechnic University. His research interests include motor drives and power electronics.

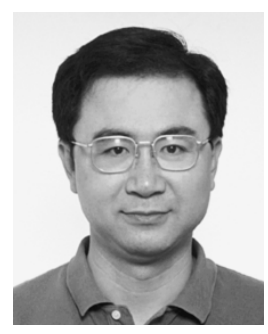

Y. M. Lai (M'92) received the B.Eng. degree in electrical engineering from the University of Western Australia, Perth, Australia, in 1983, the M.Eng.Sc. degree in electrical engineering from University of Sydney, Sydney, Australia, in 1986, and the Ph.D. degree from Brunel University, London, U.K., in 1997.

He is an Assistant Professor with Hong Kong Polytechnic University, Hong Kong, and his research interests include computer-aided design of power electronics and nonlinear dynamics.

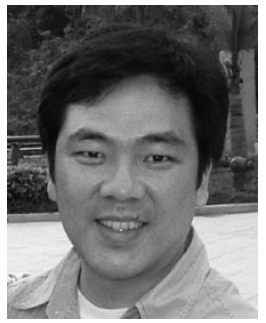

Chi K. Tse (M'90-SM'97-F'06) received the B.Eng. degree (with first class honors) and the Ph.D. degree from the University of Melbourne, Melbourne, Australia, in 1987 and 1991, respectively.

$\mathrm{He}$ is presently Chair Professor and Head of the Department of Electronic and Information Engineering, Hong Kong Polytechnic University, Hong Kong. He was a Guest Editor for Circuits, Systems and Signal Processing in 2005 and currently serves as an Associate Editor for the International Journal of Systems Science. He is the author of the books Linear Circuit Analysis (London, U.K.: Addison-Wesley, 1998) and Complex Behavior of Switching Power Converters (Boca Raton, FL: CRC Press, 2003), co-author of Chaos-Based Digital Communication Systems (Heidelberg, Germany: Springer-Verlag, 2003) and Reconstruction of Chaotic Signals with Applications to Chaos-Based Communications (Beijing, China: TUP, 2005). He is co-holder of a U.S. patent and two other pending patents. His research interests include chaotic dynamics, power electronics and chaos-based communications.

Dr. Tse received the Best Paper Award from the IEEE TRANSACTIONS ON Power Electronics in 2001, the Dynamics Days Europe Presentation Prize in 2002, and the Best Paper Award from the International Journal of Circuit Theory and Applications in 2003. In 2005, he was named an IEEE Distinguished Lecturer. He was an Associate Editor for the IEEE TRANSACTIONS ON CIRCUITS AND SYSTEMS—PART I, from 1999 to 2001, and since 1999 has been an Associate Editor for the IEEE TRANSACTIONS ON POWER EleCtronics. $\mathrm{He}$ also served as Guest Editor for the IEEE TRANSACTIONS ON CIRCUITS AND SYSTEMS-PART I, in 2003.

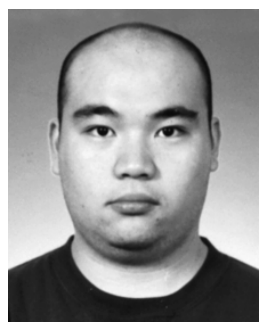

Martin K. H. Cheung (S'05) received the B.Eng. (with honors) degree and the M.Phil. degree in electronic engineering from the Hong Kong Polytechnic University, Hong Kong, in 2000 and 2003, respectively, where he is currently pursuing the Ph.D. degree in the Department of Electronic and Information Engineering.

His main research interests include RF circuit design and switch-mode power supplies design. 